\author{
R.S. Yadav $\cdot$ F.R. Bidinger $\cdot$ C.T. Hash $\cdot$ Y.P. Yadav \\ O.P. Yadav $\cdot$ S.K. Bhatnagar $\cdot$ C.J. Howarth
}

\title{
Mapping and characterisation of QTL $\times E$ interactions for traits determining grain and stover yield in pearl millet
}

Received: 3 January 2002 / Accepted: 7 June 2002 / Published online: 13 September 2002

(C) Springer-Verlag 2002

\begin{abstract}
A mapping population of $104 \mathrm{~F}_{3}$ lines of pearl millet, derived from a cross between two inbred lines H 77/833-2 × PRLT 2/89-33, was evaluated, as testcrosses on a common tester, for traits determining grain and stover yield in seven different field trials, distributed over 3 years and two seasons. The total genetic variation was partitioned into effects due to season (S), genotype $(\mathrm{G})$, genotype $\times$ season interaction $(\mathrm{G} \times \mathrm{S})$, and genotype $\times$ environment-within-season interaction $[\mathrm{G} \times \mathrm{E}(\mathrm{S})]$. QTLs were determined for traits for their $G, G \times S$, and $G \times E(S)$ effects, to assess the magnitude and the nature (cross over/ non-crossover) of environmental interaction effects on individual QTLs. QTLs for some traits were associated with $G$ effects only, while others were associated with the effects of both $\mathrm{G}$ and $\mathrm{G} \times \mathrm{S}$ and/or $\mathrm{G}, \mathrm{G} \times \mathrm{S}$ and $\mathrm{G} \times \mathrm{E}(\mathrm{S})$ effects. The major $\mathrm{G} \times \mathrm{S}$ QTLs detected were for flowering time (on LG 4 and LG 6), and mapped to the same intervals as $\mathrm{G} \times \mathrm{S}$ QTLs for several other traits (including stover yield, harvest index, biomass yield and panicle number $\mathrm{m}^{-2}$ ). All three QTLs detected for grain yield were unaffected by $\mathrm{G} \times \mathrm{S}$ interaction however. All three QTLs for stover yield (mapping on LG 2, LG 4 and LG 6) and one of the three QTLs for grain yield (mapping on LG 4) were also free of QTL $\times \mathrm{E}(\mathrm{S})$ interactions. The grain yield
\end{abstract}

Communicated by J.W. Snape

R.S. Yadav ( $\bullet$ ) C.J. Howarth

Institute of Grassland and Environmental Research (IGER),

Plas Gogerddan, Aberystwyth, Ceredigion, SY23 3EB,

United Kingdom

e-mail: rattan.yadav@bbsrc.ac.uk

Fax: +44-1970-823242

F.R. Bidinger · C.T. Hash

International Crops Research Institute

for the Semi-Arid Tropics (ICRISAT),

Patancheru 502 324, Andhra Pradesh, India

Y.P. Yadav

CCS Haryana Agricultural University, Regional Research Station, Bawal, 123 501, Haryana, India

O.P. Yadav $\cdot$ S.K. Bhatnagar

All India Co-ordinated Pearl Millet Improvement Project

(AICPMIP), ARS Mandore, Jodhpur 302 304, Rajasthan, India
QTLs that were affected by QTL $\times \mathrm{E}(\mathrm{S})$ interactions (mapping on LG 2 and LG 6), appeared to be linked to parallel QTL $\times \mathrm{E}(\mathrm{S})$ interactions of the QTLs for panicle number $\mathrm{m}^{-2}$ on (LG 2) and of QTLs for both panicle number $\mathrm{m}^{-2}$ and harvest index (LG 6). In general, QTL $\times \mathrm{E}(\mathrm{S})$ interactions were more frequently observed for component traits of grain and stover yield, than for grain or stover yield per se.

Keywords Pearl millet - Genotypexenvironment interaction - Genetic mapping - Quantitative trait loci · QTLXenvironment interaction · Marker-assisted selection

\section{Introduction}

Pearl millet [Pennisetum glaucum (L.) R. Br.] is grown by subsistence farmers as a staple food and fodder crop on 26 million ha (Anand Kumar 1989) in hot, semi-arid regions of sub-Saharan Africa and in the Indian subcontinent. Some of the major objectives of pearl millet breeding programmes are the improvement of both grain and stover yield, and yield stability, and the feeding quality of its stover for ruminants. The rate of genetic enhancement of these quantitative traits is slow because they integrate many physiological processes, have complex inheritance and their expression is strongly influenced by genotype $\times$ environment interactions. In recent years, the study of quantitative traits has been greatly facilitated by the use of molecular markers in quantitative trait locus (QTL) mapping and marker-assisted selection (Lee 1995; Mohan et al. 1997).

Genotype $\times$ environment interaction $(\mathrm{G} \times \mathrm{E})$ is the varying performance of individual genotypes across environments. $\mathrm{G} \times \mathrm{E}$ reduces the association between phenotypic and genotypic values, and leads to variable levels of the significance of QTL effects across environments (Hayes et al. 1993; Romagosa et al. 1996). QTL $\times$ environment interaction $(\mathrm{QTL} \times \mathrm{E})$ has been a subject of importance in many QTL mapping studies (Paterson et 
Table 1 Main characteristics of seven environments used to evaluate the performance of pearl millet mapping-progeny testcrosses for flowering time, and traits determining stover and grain yield. Day lengths for the seven environments were calculated at 20 days after sowing, when the crop should be capable of floral initiation. The range in the mean temperatures provided is that between the dates of sowing and harvest

\begin{tabular}{|c|c|c|c|c|c|c|c|}
\hline Environment & Year & Location, latitude & Season & $\begin{array}{l}\text { Date of sowing/ } \\
\text { harvesting }\end{array}$ & $\begin{array}{l}\text { Day } \\
\text { length }\end{array}$ & $\begin{array}{l}\text { Temperature } \\
\text { range }\left({ }^{\circ} \mathrm{C}\right)\end{array}$ & Rainfall/irrigation (mm) \\
\hline Environment 1 & 1996 & Patancheru, $17^{\circ} 45^{\prime} \mathrm{N}$ & Dry season & $16.02-08.05$ & $12^{\prime} 33^{\prime \prime}$ & $20.6-36.2$ & Irrigated weekly \\
\hline Environment 2 & 1997 & Patancheru, $17^{\circ} 45^{\prime} \mathrm{N}$ & Dry season & $27.01-25.04$ & $12^{\prime} 19^{\prime \prime}$ & $17.3-33.6$ & Irrigated weekly \\
\hline Environment 3 & 1997 & Patancheru, $17^{\circ} 45^{\prime} \mathrm{N}$ & Rainy season & 18.06-29.09 & $13^{\prime} 56^{\prime \prime}$ & $22.2-29.5$ & Supplementally irrigated \\
\hline Environment 4 & 1997 & Bawal, $28^{\circ} 12^{\prime} \mathrm{N}$ & Rainy season & 03.07-20.09 & $14^{\prime} 31^{\prime \prime}$ & Data not available & $352 \mathrm{~mm}$ (22 rainy days) \\
\hline Environment 5 & 1997 & Mandore, $26^{\circ} 30^{\prime} \mathrm{N}$ & Rainy season & $13.07-30.09$ & $14^{\prime} 05^{\prime \prime}$ & $22.5-30.9$ & 358 mm (34 rainy days) \\
\hline Environment 6 & 1998 & Patancheru, $17^{\circ} 45^{\prime} \mathrm{N}$ & Dry season & $23.02-08.05$ & $12^{\prime} 45^{\prime \prime}$ & $21.3-36.9$ & Irrigated weekly \\
\hline Environment 7 & 1998 & Patancheru, $17^{\circ} 45^{\prime} \mathrm{N}$ & Dry season & $23.02-05.05$ & $12^{\prime} 45^{\prime \prime}$ & $21.3-36.9$ & Irrigated weekly \\
\hline
\end{tabular}

al. 1991; Bubeck et al. 1993; Lee et al. 1996; Lu et al. 1996; Yan et al. 1999; Cao et al. 2001). QTL $\times$ E in these studies resulted in either significant QTL effects being detected only in a subset of all the environments, or in changes in magnitude of the QTL effect (non-crossover) or changes in QTL effects across environments in rank (crossover, i.e. alternate alleles demonstrating a favourable effect in different environments). When environment significantly modifies QTL effects, marker-assisted selection schemes specific to environments may be necessary. Until recently, the existence of QTL $\times$ E interactions in most mapping studies was inferred by comparing QTLs and their effects in multiple environments (e.g. studies reported by Paterson et al. 1991; Bubeck et al. 1993; Lee et al. 1996; Lu et al. 1997). However, Yan et al. (1999) have shown that QTLs determined from across-environment trait means are likely to be biased, as they may include $\mathrm{G} \times \mathrm{E}$ interaction effects in addition to genotype main effects. Also QTL analysis on acrossenvironment trait means provides no information on the existence, magnitude or the nature of QTL $\times \mathrm{E}$ interactions occurring for individual QTLs (Zhu 1998; Yan et al. 1999; Cao et al. 2001). Yan et al. (1999) have proposed a new analysis methodology in which the total genetic variance is first partitioned into effects due to genotype $(G)$ and to $G \times E$ interactions, and QTLs are then mapped to these effects separately. QTLs mapping to G effects only are those that are independent of changes in environmental conditions, while those mapping to $\mathrm{G} \times \mathrm{E}$ interaction effects are those that are significantly affected by changes in environmental conditions (Yan et al. 1999; Cao et al. 2001). This approach to QTL analysis both distinguishes QTLs that are, and are not, affected by variation in environment, and also provides information on the magnitude and the nature (crossover or noncrossover) of the identified QTL $\times$ E interactions.

The present study was designed to assess $\mathrm{G} \times \mathrm{E}$ interactions for traits determining grain and stover yields in pearl millet in seven different environments. QTLs were determined for $G$ and $G \times E$ effects separately, to understand how changes in environment affected QTL expression. Results obtained are discussed in the light of the use of marker-assisted selection for improvement of these traits in breeding programmes.

\section{Materials and methods}

\section{Plant material}

The experiment included 104 testcross hybrids (TCs), the seed of which was produced by crossing pollen from 104 mapped, $\mathrm{F}_{2}$-derived $\mathrm{F}_{3}$ progenies onto a common male-sterile line tester (843A, Stegmeier et al. 1998). Characteristics of the mappingpopulation parents (H 77/833-2 and PRLT 2/89-33) and details of the mapping-population and the genetic linkage map are described in Yadav et al. (2002).

\section{Environments}

The 104 mapping progeny testcross hybrids (genotypes) were evaluated in seven different trials (hereafter referred to as environments) over a 3-year period (Table 1). The seven environments differed with respect to the latitude of the locations (northern and southern India), the seasons in which experiments were conducted (dry and rainy seasons) and the years (1996 to 1998) in which the trials were conducted. The trials were conducted at three locations: at Bawal and Mandore in northern India, and at Patancheru in southern India. All trials except those conducted at Bawal and Mandore (environments 4 and 5) were grown under irrigated conditions upon sowing to maturity as described in Yadav et al. (2002). Trials at Bawal and Mandore were grown under rainfed conditions.

\section{Agronomic evaluation}

In all seven environments, TCs were evaluated in randomised complete block design field trials with three replications. Trials in environments $1,2,4$ and 5 had plots of 2 rows $\times 0.6 \mathrm{~m} \times 4.0 \mathrm{~m}$, and those in environments 3,6 and 7 had plot sizes of 1 row $\times$ $0.6 \mathrm{~m} \times 4.0 \mathrm{~m}$. Intra-row spacing was maintained at a uniform 0.15 to $0.20 \mathrm{~m}$ in all trials, resulting in a plant stand of approximately $8-10$ plants $\mathrm{m}^{-2}$. Flowering time (FT) was recorded for each plot as days from seedling emergence to stigma emergence in $50 \%$ of the main shoot panicles. At harvest, data were recorded on plant numbers, panicle numbers and stover fresh mass. Panicle and grain dry mass were recorded after oven drying for approximately $72 \mathrm{~h}$; stover dry mass was estimated from plot stover fresh weights using the fresh and dry weights of a chopped sub-sample of stover from each plot.

\section{Statistical analysis}

The data set involved 104 mapping population TCs and seven evaluation environments distributed among three locations, two seasons and 3 years (Table 1). Because of the unbalanced nature of the environmental data set, and the consequent few degrees of 
freedom for most combinations of season, location and year, only the effects due to season $(1 d f)$, and environment within season $(5 d f)$, were considered in the analysis of both $\mathrm{E}$ and $\mathrm{G} \times \mathrm{E}$ effects. All environmental effects were considered random. Combined analysis of variance was performed using GENSTAT (GENSTAT 5 Committee 1993) to determine the significance of variation due to $\mathrm{E}$ [S and $\mathrm{E}(\mathrm{S})], \mathrm{G}$ and $\mathrm{G} \times \mathrm{E}[\mathrm{G} \times \mathrm{S}$ and $\mathrm{G} \times \mathrm{E}(\mathrm{S})]$ on each trait evaluated. Effects due to $G, G \times S$ and $G \times E(S)$ were calculated as described in Yan et al. (1999). Briefly, the phenotypic performance of the $\mathrm{k}^{\text {th }}$ genotype in the $\mathrm{h}^{\text {th }}$ environment within the $\mathrm{j}^{\text {th }}$ season was fitted to the following statistical model:

$$
\begin{aligned}
\mathrm{Y}_{\mathrm{hjk}}= & \mu+\mathrm{S}_{\mathrm{j}}+\mathrm{E}(\mathrm{S})_{\mathrm{h}(\mathrm{j})}+\mathrm{G}_{\mathrm{k}}+(\mathrm{GS})_{\mathrm{jk}} \\
& +(\mathrm{GE}(\mathrm{S}))_{\mathrm{k}(\mathrm{hj})}+\mathrm{e}_{\mathrm{hjk}},
\end{aligned}
$$

where $\mu$ is the population mean, $S_{j}$ is the effect of the $j^{\text {th }}$ season, $E(S)_{h(j)}$ is the effect of the $h^{\text {th }}$ environment within the $j^{\text {th }}$ season, $G_{k}$ is the effect of the $\mathrm{k}^{\text {th }}$ genotype, (GS) $)_{\mathrm{jk}}$ is the interaction of the $\mathrm{k}^{\mathrm{th}}$ genotype and the $\mathrm{j}^{\text {th }}$ season, $(\mathrm{GE}(\mathrm{S}))_{\mathrm{k}(\mathrm{hi})}$ is the interaction of the $\mathrm{k}^{\text {th }}$ genotype and the $h^{\text {th }}$ environment within the $j^{\text {th }}$ season and $e_{h j k}$ is the residual effect.

QTL mapping was performed on the $\mathrm{G}, \mathrm{G} \times \mathrm{S}$ and $\mathrm{G} \times \mathrm{E}(\mathrm{S})$ effect means, using the method of interval mapping (Lander and Botstein 1989). The $\mathrm{G}$ main effect of traits are the accumulated effect expressed in the same way across different environments, while the $\mathrm{G} \times \mathrm{S}$ and $\mathrm{G} \times \mathrm{E}(\mathrm{S})$ interaction effects are the deviation due to specific seasons and specific environments within a season respectively. The additive genetic model in MAPMAKER-QTL was used to analyse QTLs in the TC progenies (Beavis et al. 1994; Yadav et al. 2002)

\section{Results}

Agronomic trait expressions in different environments

Means and ranges of the traits evaluated in seven different environments are presented in Table 2. Seasonal mean values were similar for flowering time, biomass and stover yields, but dry season means for panicle number (in particular), grain yield and the harvest index were higher than those for the rainy season (Table 2). Differences in panicle number were due to the much-lower number of productive tillers in the northern Indian rainy season locations (environments 4 and 5). The lower rainy season mean-grain yield and mean-harvest index values were due to much-lower values of both of these traits at environment 4 than at any of the other locations, including environment 5 , despite an only slightly lower biomass productivity (Table 2). Apart from these mean values, most of the traits for the 104 TCs were roughly similar across the other locations.

Sources of variation in trait performance across environments are presented in Table 3. For most traits, season accounted for a small proportion of total environmental variation, ranging from $0 \%$ of the total mean sums of squares for flowering time to $23 \%$ for panicle number $\mathrm{m}^{-2}$. Season was a significant source of variation for panicle number, biomass, harvest index and grain yield (Table 3). In contrast, environment within season accounted for $99 \%$ of the total environmental variation in flowering time, and between $76 \%$ to $89 \%$ of the variation in the rest of the traits evaluated (Table 3). Although season contributed relatively little to total environmental

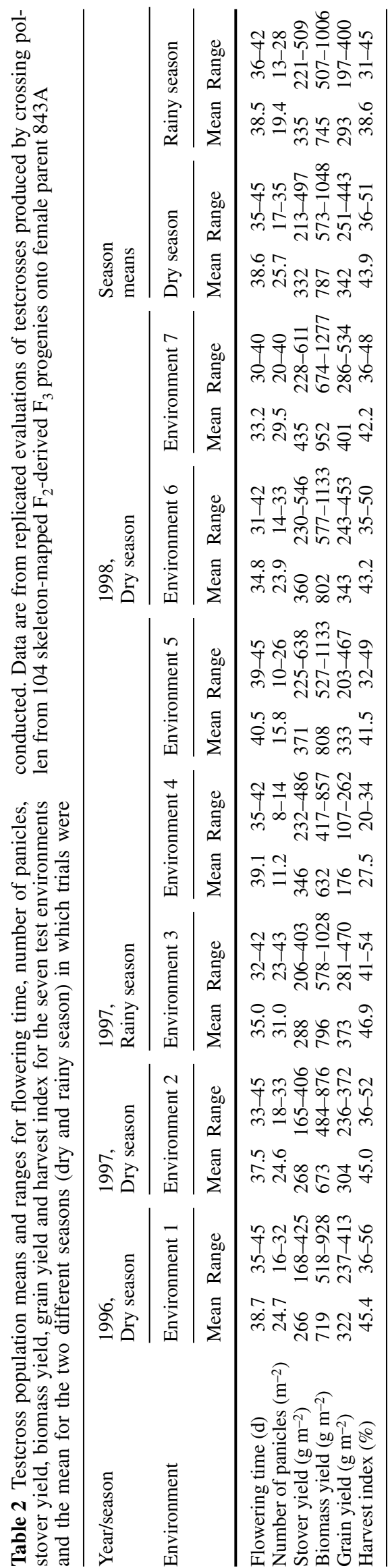


Table 3 Proportion of environment and genotype $\times$ environment interaction mean sum of squares accounted by variations in environmental factors (season and environments within seasons), genotypes (testcrosses) and their interactions in the expression of grain and stover yield determining traits in pearl millet. Testcrosses of skeleton-mapped $\mathrm{F}_{2}$-derived $\mathrm{F}_{3}$ progenies from a pearl millet mapping population based on a cross between $\mathrm{H} 77 / 833-2 \times$ PRLT 2/89-33 were subject to multi-environment evaluations

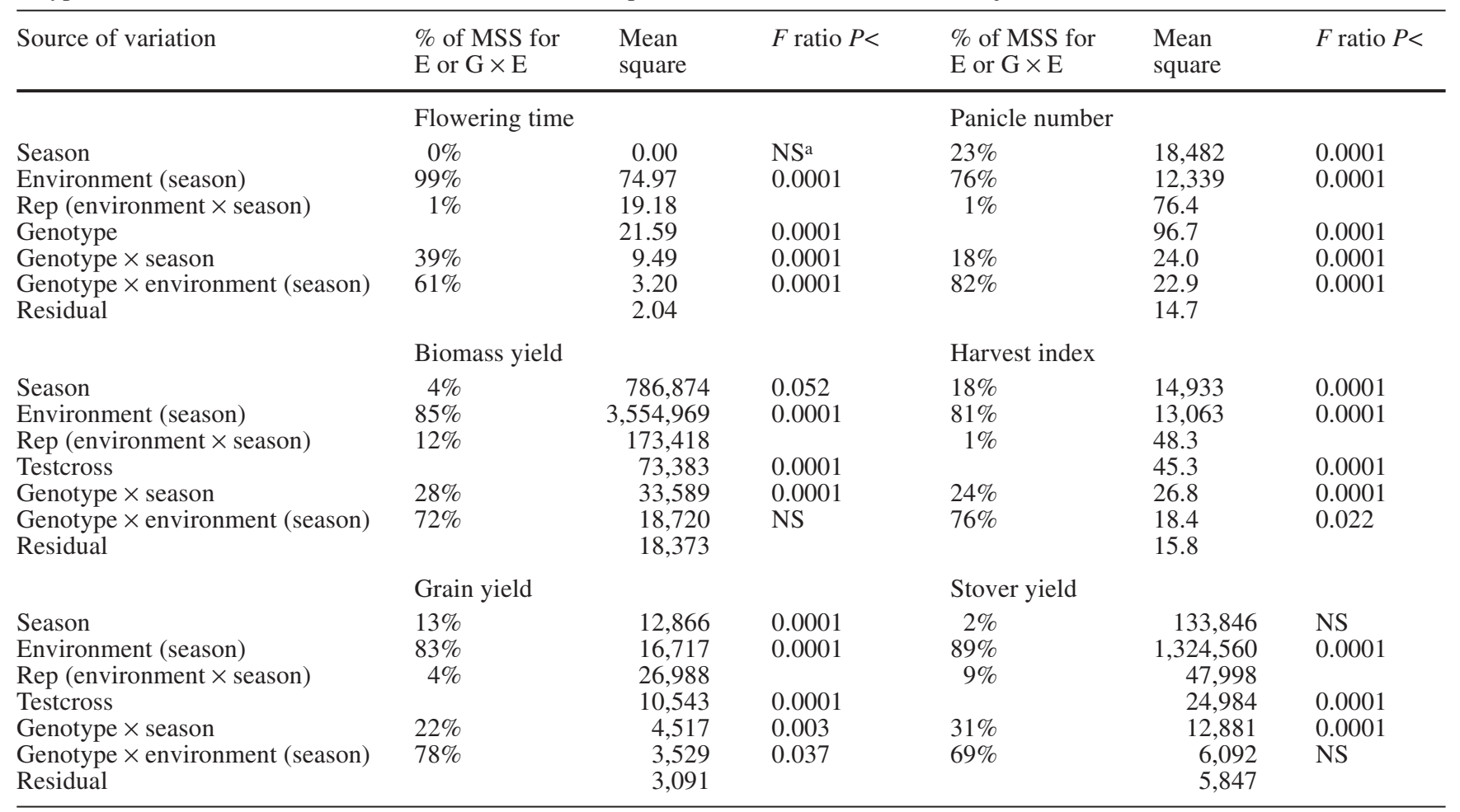

a NS $=P>0.10$

Table 4 Correlation coefficients of between flowering time, and pearl millet grain and biomass yield traits, in individual environments of dry and rainy season trials as described in Table 1. Critical values for correlation coefficients are $0.19,0.23$ and 0.26 for $P<0.05, P<0.01$ and $P<0.001$ respectively

\begin{tabular}{lllllr}
\hline Environment & $\begin{array}{l}\text { Panicle } \\
\text { number } \mathrm{m}^{-2}\end{array}$ & $\begin{array}{l}\text { Stover } \\
\text { yield }\end{array}$ & $\begin{array}{l}\text { Biomass } \\
\text { yield }\end{array}$ & $\begin{array}{l}\text { Grain } \\
\text { yield }\end{array}$ & $\begin{array}{r}\text { Harvest } \\
\text { index }\end{array}$ \\
\hline Dry Season & & & & & \\
1 & -0.07 & 0.46 & 0.22 & 0.04 & -0.37 \\
2 & -0.22 & 0.69 & 0.48 & 0.19 & -0.48 \\
6 & -0.19 & 0.40 & 0.32 & 0.17 & -0.23 \\
7 & -0.13 & 0.38 & 0.37 & 0.31 & -0.11 \\
Rainy Season & & & & & \\
3 & -0.30 & -0.19 & -0.31 & -0.32 & -0.11 \\
4 & -0.13 & -0.27 & -0.27 & -0.17 & 0.00 \\
5 & -0.32 & -0.22 & -0.28 & -0.26 & -0.05 \\
\hline
\end{tabular}

variation, it was a more-important source of $\mathrm{G} \times \mathrm{E}$ variation. $\mathrm{G} \times \mathrm{S}$ accounted for between $18 \%$ (panicle number) and $39 \%$ (time to flowering) of the total mean sums of squares for $\mathrm{G} \times \mathrm{E}$ for all traits, and was a significant source of variation for all traits (Table 3). However $\mathrm{G} \times \mathrm{E}(\mathrm{S})$ still accounted for a larger fraction of the total mean sums of squares for $\mathrm{G} \times \mathrm{E}$ for all traits than did $\mathrm{G} \times \mathrm{S}$, ranging from $61 \%$ for flowering time to $82 \%$ for panicle number $\mathrm{m}^{-2}$, and was statistically significant for all traits except stover and biomass yield (Table 3 ).

Grain, stover and biomass yields were consistently positively associated with each other, and with productive tiller number, in all environments (data not shown). The relationship of harvest index and grain yield was also consistently positive (and that of harvest index and stover yield was consistently negative) in all environments. In contrast, the relationship between flowering time and stover, grain and biomass yields in the two seasons was quite different: later flowering was associated with increased yields in the dry season environments but with decreased yields in the rainy season environments (Table 4). This did not appear to be due directly to a differential effect of flowering time on productive tiller numbers in the two seasons, as panicle number generally decreased with later flowering in both seasons, although this relationship was more consistent in the rainy season environments where yields also decreased with later flowering (Table 4). Similarly, there was a different rela- 
tionship between flowering time and harvest index between the two seasons with no significant correlation between the two traits in the rainy season trials, whereas there was a negative correlation between flowering time and harvest index in the dry season trials (Table 4). This differential effect of seasons also appears in terms of large QTL $\times$ S interactions for the flowering-time QTLs (see below).

QTL mapping and characterisation

\section{QTLs associated with genotype main effects of traits}

The results of QTL mapping of genotype main effects (G QTL) are presented in Table 5. G QTLs for flowering time mapped to linkage group (LG) 4 and LG 6. For the G QTL on LG 4, the H 77 parental allele was associated with later flowering, while at the G QTL on LG 6, the PRLT parental allele was associated with later flowering. G QTLs for stover yield, grain yield and biomass yield co-mapped with flowering time G QTLs (Table 5; Fig. 1), and the parental alleles associated with later flowering were also associated with increased stover, grain and biomass yields on both LG. Similarly, G QTLs for panicle number $\mathrm{m}^{-2}$ and harvest index co-mapped with the flowering time G QTL on LG 6. The parental allele associated with later flowering at this QTL was also associated with increased stover, grain and biomass yields, but, in contrast to LG 4, was associated with decreased panicle number $\mathrm{m}^{-2}$ and harvest index.

Three more G QTLs for panicle number $\mathrm{m}^{-2}$ were identified in this study. They mapped to LG 1, LG 2 and LG 7. Unlike the G QTL for panicle number $\mathrm{m}^{-2}$ mapping on LG 6, those on LG 1, LG 2 and LG 7 were independent of flowering time, i.e. did not co-map with flowering-time QTLs (Table 5). The G QTL for panicle number $\mathrm{m}^{-2}$ on LG 2 co-mapped with G QTLs for grain, stover and biomass yield, and the $\mathrm{H} 77$ parental alleles at this map position were associated with increased panicle number $\mathrm{m}^{-2}$, stover, grain and biomass yield (Table 5). Evidently this QTL affects either the number of tillers produced or (more likely) the fraction of tillers continuing development to maturity, and consequently stover, grain and biomass yields.

\section{QTLs associated with $G \times S$ interaction effects of traits}

There were significant QTL $\times \mathrm{S}$ interactions for the flowering-time QTLs mapping to LG 4 and LG 6; in both cases, these interactions were of the crossover type (Table 5). For the QTL on LG 4, the H 77 allele resulted in later flowering time in the dry season, but in the rainy season the alternate PRLT allele resulted in later flowering time. Conversely, on LG 6, the PRLT allele delayed flowering time in the dry season, and the $\mathrm{H} 77$ allele delayed flowering time in the rainy season. Clearly therefore, the effects on flowering time of the two parental
Linkage Group 2
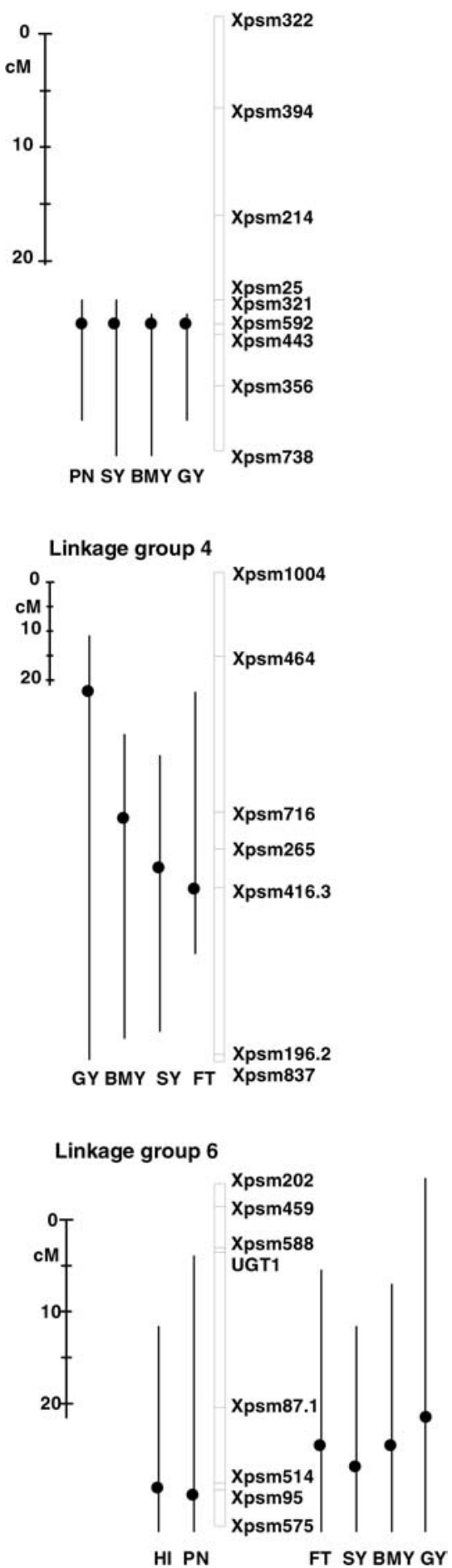

Fig. 1 Map locations of genotype main-effect (G) QTLs of grain and stover yield determining traits in pearl millet mapping population H 77/833-2 $\times$ PRLT 2/89-33. For each linkage group a scale of genetic distance in Haldane cM is provided. One-LOD support intervals are indicated by vertical bars with the position of the maximum LOD peak indicated by $\bullet$. QTLs in which the PRLT parental allele conferred an increased trait value are indicated on the right- hand side of the linkage map, and those in which the $\mathrm{H} 77$ parental allele increased the trait value is on the left- hand side. FT Flowering time, $G Y$ Grain yield $\mathrm{m}^{-2}, S Y$ Stover yield $\mathrm{m}^{-2}$, $B M Y$ Biomass yield $\mathrm{m}^{-2}, P N$ Panicle number $\mathrm{m}^{-2}, H I$ Harvest index 


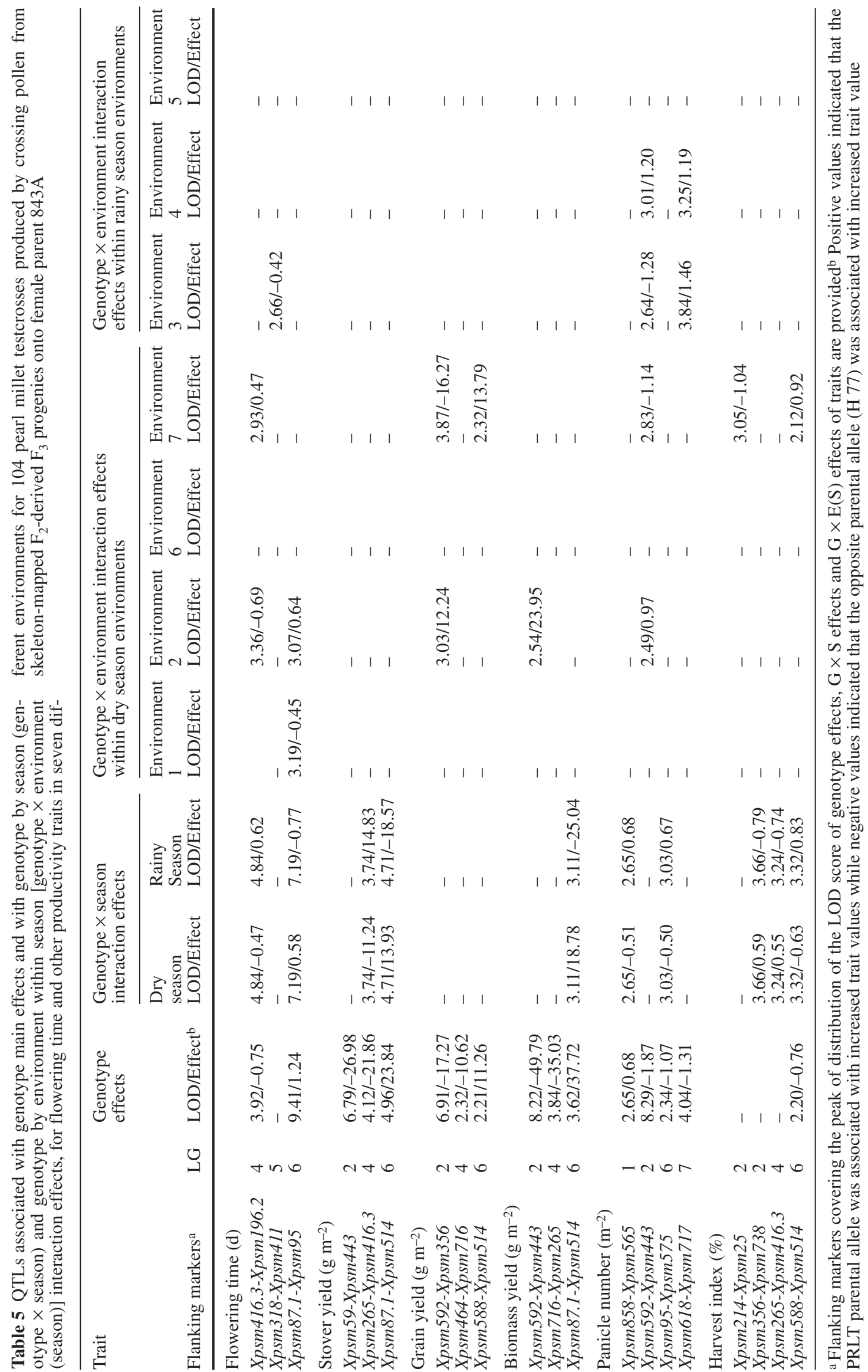


alleles at these flowering QTLs on both LG 4 and LG 6 are dependent on the differences in environmental (day length and/or temperature) conditions in the two seasons.

The QTL $\times$ S effects for the flowering-time QTLs on LG 4 and LG 6 co-mapped with the QTL $\times$ S effects on stover yield and harvest index (Table 5). For both intervals, parental alleles associated with later flowering-time were associated with increased stover yield but reduced harvest index. As a result, QTL $\times \mathrm{S}$ effects for both of these flowering-time QTLs were not accompanied by QTL $\times$ S effects for grain yield (Table 5). In addition, QTL $\times$ S effects for the flowering-time QTL on LG 6 co-mapped with the QTL $\times$ S effects on biomass yield and panicle number $\mathrm{m}^{-2}$, with later flowering again associated with increased biomass yield, but with reduced panicle numbers $\mathrm{m}^{-2}$ (Table 5). Longer day lengths, such as those encountered at the rainy season locations (Table 1), have previously been reported to both delay flowering and to reduce the numbers of productive tillers in pearl millet (Craufurd and Bidinger 1988b). Crossover QTL $\times$ S effects were also evident for the G QTL for panicle number $\mathrm{m}^{-2}$ on LG 1 , which was not related to flowering time (Table 5). In addition, a season specific QTL was identified for the harvest index on LG 2.

\section{$Q T L s$ associated with $G \times E(S)$ interaction effects of traits}

The flowering-time QTLs mapping on LG 4 and LG 6 were unaffected by the individual rainy season environments (environments 3, 4 and 5) but showed significant QTL $\times$ E [i.e. QTL $\times \mathrm{E}(\mathrm{S})]$ interactions with some of the dry season environments. The flowering-time QTLs on LG 4 and LG 6 showed a similar (non-crossover) interaction in dry season environment 2 as they did in the dry season in general, but a crossover interaction was observed for the QTL on LG 4 in dry season environment 7 and for that on LG 6 in the dry season environment 1 (Table 5). Environment 2 experienced the shortest day length and the coolest temperatures of any test environment in this set of trials. This would have promoted early flowering of those genotypes that would have delayed flowering in relatively longer photoperiods, whilst the higher temperatures of the other three dry season environments would accentuate this difference in floweringtime response. Although these QTL $\times \mathrm{E}(\mathrm{S})$ interactions for the LG 4 and LG 6 flowering-time QTLs were significant, they were not associated with QTL $\times \mathrm{E}(\mathrm{S})$ effects for stover, grain or biomass yields (Table 5).

A new QTL for flowering time was identified on LG 5 in rainy season environment 3 , the only test environment conducted in Southern India in the rainy season. This QTL was specific to the environmental conditions of this environment, as no $\mathrm{G}$ or $\mathrm{G} \times \mathrm{S}$ QTLs for flowering time were detected on this linkage group (Table 5). The H 77 allele at this QTL on LG 5 increased flowering time. This QTL was neither associated with grain and stover yields nor with any of their component traits.
A significant $\mathrm{QTL} \times \mathrm{E}(\mathrm{S})$ interaction was evident for the grain yield QTL on LG 2 in (dry season) environments 2 and 7, and for the grain yield QTL on LG 6 in environment 7 (Table 5). The QTL $\times \mathrm{E}(\mathrm{S})$ interaction for the grain yield QTL on LG 2 was accompanied by similar QTL $\times \mathrm{E}(\mathrm{S})$ interactions for the biomass yield and panicle number $\mathrm{m}^{-2}$ QTLs mapping to the same region of LG 2 in environment 2 , and by a QTL $\times \mathrm{E}(\mathrm{S})$ interaction for the panicle number $\mathrm{m}^{-2}$ QTL mapping to the same region on LG 2 in environment 7 (Table 5). Similarly, the $\mathrm{QTL} \times \mathrm{E}(\mathrm{S})$ interaction for the grain yield QTL on LG 6 was accompanied by a QTL $\times E(S)$ interaction for the harvest-index QTL mapping to the same region of LG 6 in environment 7. It was therefore likely that the primary QTL $\times \mathrm{E}(\mathrm{S})$ interactions were on productive tiller number, biomass yield and/or harvest index, and these in turn caused analogous QTL $\times \mathrm{E}(\mathrm{S})$ interactions on grain yield. QTL $\times \mathrm{E}(\mathrm{S})$ interactions also occurred for the QTLs for panicle number $\mathrm{m}^{-2}$ on LG 2 and LG 7 in rainy season environments 3 and 4, but they were not accompanied by parallel QTL $\times \mathrm{E}(\mathrm{S})$ interactions for stover, biomass or grain yields (Table 5).

\section{Discussion}

In this study, most QTLs associated with $G$ effects of traits mapped to LG 2, LG 4 and LG 6. The G QTLs for stover, grain and biomass yields co-mapped with the G QTLs for panicle number $\mathrm{m}^{-2}$ (on LG 2 and 6), and to G QTLs for flowering time on LG 4 and LG 6 (Fig. 1). QTLs of component traits (such as flowering time and panicle number $\mathrm{m}^{-2}$ ) co-mapping with stover and grain yield QTLs suggested their involvement in determining these traits. An increase in time to flowering (QTLs on LG 4 and LG 6) would be expected to increase stover and biomass yield (Craufurd and Bidinger 1988a), and this was supported by the finding that the parental alleles increasing flowering time on these LGs were also associated with increased stover, grain and biomass yields. Similarly, on LG 6 the QTL for panicle number $\mathrm{m}^{-2}$ comapped with QTLs for grain, stover and biomass yield.

Both flowering-time G QTLs (LG 4 and LG 6) were significantly affected by season, and the QTL $\times$ S interaction observed for flowering was accompanied by a parallel interaction for the two QTLs for stover yield, which mapped to the same intervals on the these LGs. This, however, was not found with the QTLs for grain yield (Table 5). This was mainly because the QTL $\times$ S interaction on flowering time was accompanied by a parallel, but opposite, QTL $\times$ S interaction on the QTLs for harvest index at these intervals, such that an increase in stover (and biomass, at least in the case of the QTL on LG 6) was accompanied by a decline in harvest index, leaving grain yields unchanged. Such interactions among yield components, with little or no effect on final yield, are common in cereals, because of compensatory relationships among sequentially developing yield components (Adams 1967). These positive relationships be- 
tween yield and the yield component G QTL on LG 4 and LG 6 very likely represent an indirect effect of laterflowering, which resulted in a longer vegetative growth period and increased biomass yields. Dry matter accumulation is increased in later-flowering genotypes but this does not necessarily result in increased grain yield because the additional dry matter is partitioned to stem rather than to grain growth, thus reducing harvest index (Crauford and Bidinger 1988b). The later-flowering allele for the G QTL on LG 6 has previously been reported to be associated with a reduced panicle number $\mathrm{m}^{-2}$, but an increased number of grains per panicle (Yadav et al. 1999). In that study these two component effects offset each other and the QTL had no effect on grain yield, as found in this study.

There were QTL $\times$ S interactions for two of the four QTLs for panicle number $\mathrm{m}^{-2}$ (Table 5). Interestingly, the strongest of these QTLs, on LG 2, was independent of flowering-time QTLs and was not affected by season. Further, it was also the only QTL for panicle number $\mathrm{m}^{-2}$ co-mapping with QTLs for stover, biomass and grain yields. Like that for panicle number $\mathrm{m}^{-2}$, the associated QTLs for stover, biomass and grain yield on LG 2 were not affected by season, making this genomic region of particular interest for areas where improving productive tillering is a breeding-programme objective.

The QTL for panicle number $\mathrm{m}^{-2}$ on LG 6, was linked to a flowering-time QTL, for which the allele for later flowering was associated with reduced panicle number. This was probably a result of delayed flowering extending the period of apical dominance of the main shoot. Alleles for delayed flowering and reduced panicle number were in turn associated with increased stover yield and increased biomass yield, but with reduced harvest index and reduced grain yield, making this QTL of less interest for yield improvement.

QTL $\times \mathrm{E}(\mathrm{S})$ interactions occurred for various QTLs when the G QTL effects and/or QTL $\times$ S interactions for flowering time and other stover and grain yield determining component traits were not consistent across all the test environments within a particular season. For example, the flowering-time QTLs on LG 4 and LG 6 (which had significant QTL $\times$ S interactions), also had $\mathrm{QTL} \times \mathrm{E}(\mathrm{S})$ interactions in dry season environments 1 and 2, but were free of QTL $\times \mathrm{E}(\mathrm{S})$ interactions in rainy season environments (Table 5). However, significant QTL $\times \mathrm{E}(\mathrm{S})$ interactions were not universally the case. QTL $\times \mathrm{E}(\mathrm{S})$ interactions clearly resulted from other, less well understood, differences among environments that may not have been related to gross seasonal differences such as day length, temperature or radiation. The question is whether these QTL $\times \mathrm{E}(\mathrm{S})$ interactions are random differences that cannot be addressed in a crop improvement program, or the result of predictable ones which need to be.

All three QTLs for stover yield were free of QTL $\times$ $\mathrm{E}(\mathrm{S})$ interactions, and only the biomass QTL on LG 2 was subject to a significant QTL $\times \mathrm{E}(\mathrm{S})$, in dry season environment 7 , where it was accompanied by a similar interaction for panicle number $\mathrm{m}^{-2}$. Interestingly, the majority of QTLs detected were free of QTL $\times \mathrm{E}(\mathrm{S})$ interactions in rainy season environments. All three QTLs for grain yield were free of both QTL $\times \mathrm{S}$ interactions and $\mathrm{QTL} \times \mathrm{E}(\mathrm{S})$ interactions in the rainy season environments. The grain yield QTL on LG 4 was free of QTL $\times$ $\mathrm{E}(\mathrm{S})$ interactions in all environments, and the grain yield QTL on LG 2 and LG 6 were subject to QTL $\times E(S)$ interactions only in dry season environments 2 (LG 2) and 7 (LG 2 and LG 6). However these interaction effects were small, and in only one case (LG 2 in environment 7) was the QTL $\times E(S)$ interaction of a crossover type. Non-crossover interactions are not considered that serious in plant breeding programmes, as they affect only the magnitude and not the direction of effects in different environments. The occurrence of QTL $\times \mathrm{E}(\mathrm{S})$ interactions only in the dry season is a bit surprising, in that all of the dry season environments were at a single location (Patancheru) whereas the rainy season environments were all in different locations, which spanned 10 degrees of latitude (Table 1). This is a useful finding, as pearl millet is grown almost entirely as a rainy season crop in most parts of the semi-arid tropics; stable QTLs identified in rainy season environments are likely to have wide application in the target environments. However, it does raise some questions about the use of dry season test environments for QTL identification.

\section{Conclusions}

Three types of QTLs were detected in this study. The first type was associated with $\mathrm{G}$ effects for various traits, but not with either $\mathrm{G} \times \mathrm{S}$ or $\mathrm{G} \times \mathrm{E}(\mathrm{S})$ interaction effects. These included QTLs for grain and biomass yield on LG 4 and for a stover yield QTL on LG 2. Because the expression of such QTLs is free from environmental interactions, their use in selection will change/improve trait performances across all environments included in this study.

The second type of QTL identified was associated with traits in either a specific season or a specific environment. QTLs in this category included that for flowering time on LG 5 and those for harvest index on LG 2 and LG 4. Expression of such QTLs is specific to a particular set of environmental conditions, and they will be suitable for selection of performance in those specific environments only.

The third type of QTLs identified were associated with both $\mathrm{G}$ and $\mathrm{G} \times \mathrm{E}$ effects; many of the QTLs identified in this study fell in this category. The expression of such QTLs is dependent on environmental conditions and their application in marker-assisted breeding programs would require careful consideration. However, if the QTL $\times$ E interactions were of a non-crossover type, or relatively small, selection would still contribute to gains in performance across environments, albeit with variable responses in particular environments. However, if the interaction were of the crossover type and relative- 
ly large, selecting for one parental allele could result in an undesired result in certain environments. The alternative would be to select alternative parental alleles for different sites/environments, which would be recommended only for clearly defined, major target environments, where different alleles had major effects.

Agricultural researchers have long recognised the implications of genotype $\times$ environment interactions in breeding programmes (for a review see Kang 1998). In this report we have used a methodology which has made it possible to identify the interaction of individual environmental variations on QTLs underlying a complex phenotype such as grain yield. Such information would help breeders in deciding which QTL to use in their breeding programmes while tailoring crop cultivars for specific or more diverse environments.

Acknowledgements The authors thank Kirsten Skøt and P.V.M.D. Maheshwar Rao for their assistance during the field trials. This document is an output from a project (Plant Sciences Research Programme R6451) funded by the UK Department for International Development (DFID) and administered by the Centre for Arid Zone Studies (CAZS) for the benefit of developing countries. The views expressed are not necessarily those of DFID.

\section{References}

Adams MW (1967) Basis of yield component compensation in crop plants with special reference to the field bean Phaseolus vulgaris. Crop Sci 7:505-510

Anand Kumar K (1989) Pearl millet: status and future potential. Outlook Agric 18:46-53

Beavis WD, Smith OS, Grant D, Fincher R (1994) Identification of quantitative trait loci using a small sample of topcrossed and $\mathrm{F}_{4}$ progeny from maize. Crop Sci 34:882-896

Bubeck DM, Goodman MM, Beavis WD, Grant D (1993) Quantitative trait loci controlling resistance to gray leaf spot in maize. Crop Sci 33:838-847

Cao G, Zhu J, He C, Gao Y, Yan J, Wu P (2001) Impact of epistasis and QTL $\times$ environment interaction on the development behaviour of plant height in rice (Oryza sativa L.). Theor Appl Genet 103:153-160

Craufurd PQ, Bidinger FR (1988a) Effect of the duration of the vegetative phase on shoot growth, development and yield in two contrasting pearl millet hybrids. J Agric Sci Camb 110:71-79

Craufurd PQ, Bidinger FR (1988b) Effect of the duration of the vegetative phase on crop growth, development and yield in pearl millet [Pennisetum americanum (L.) Leeke]. J Exp Bot 198:124-139
GENSTAT 5 Committee (1993) GENSTAT 5 reference manual. Clarendon Press, Oxford, UK

Hayes PM, Liu BH, Knapp SJ, Chen FQ, Jones B, Blake TK, Franckowiak JD, Rasmusson DC, Sorrels M, Ullrich SE, Wesenberg D, Kleinhofs A (1993) Quantitative trait locus effects and environmental interaction in a sample of North American barley germplasm. Theor Appl Genet 87:329-401

Kang MS (1998) Using genotype by environment interaction for crop cultivar development. Adv Agron 62:199-252

Lander ES, Botstein D (1989) Mapping Mendelian factors underlying quantitative traits using RFLP linkage maps. Genetics 121:185-199

Lee M (1995) DNA markers and plant breeding programs. Adv Agron 55:265-344

Lee SH, Bailey MA, Mian MAR, Carter TE, Ashley DA, Hussey RS, Parrott WA, Boerma HR (1996) Molecular markers associated with soybean plant height, lodging, and maturity across locations. Crop Sci 36:728-735

Lu C, Shen L, Tan Z, Xu Y, He P, Chen Y, Zhu L (1996) Comparative mapping of QTL for agronomy traits of rice across environments using a double haploid population. Theor Appl Genet 93:1211-1217

Mohan M, Nair S, Bhagwat A, Krishna TG, Yano M (1997) Genome mapping, molecular markers and marker-assisted selection in crop improvement. Mol Breed 3:87-103

Paterson A, Damon S, Hewitt JD, Zamir D, Robinowich HD, Lincoln S, Lander ES, Tanksley SD (1991) Mendelian factors underlying quantitative traits in tomato: comparison across species, generations, and environments. Genetics 127:181-197

Romagosa I, Ullrich SE, Hann F, Hayes MH (1996) Use of the additive main effects and multiplicative interaction model in QTL mapping for adaptation in barley. Theor Appl Genet 93:30-37

Stegmeier WD, Andrews DJ, Rai KN, Hash CT (1998) Pearl millet parental lines 843A and 843B. Int Sorghum Millets Newslett 39:129-130

Veldboom LR, Lee M (1996) Genetic mapping of quantitative trait loci in maize in stress and nonstress environments. I. Grain yield and yield components. Crop Sci 36:1310-1319

Yan J, Zhu J, He C, Benmoussa M, Wu P (1999) Molecular markerassisted dissection of genotype $\times$ environment interaction for plant type traits in rice (Oryza sativa L.). Crop Sci 39:538544

Yadav RS, Hash CT, Bidinger FR, Howarth CJ (1999) QTL analysis and marker-assisted breeding of traits associated with drought tolerance in pearl millet. In: Ito O, O'Toole J, Hardy B (eds) Genetic improvement of rice for water-limited environments. International Rice Research Institute (IRRI): Los Baños, The Philippines, pp 211-223

Yadav RS, Hash CT, Bidinger FR, Cavan GP, Howarth CJ (2002) Quantitative trait loci associated with traits determining grain and stover yield in pearl millet under terminal drought stress conditions. Theor Appl Genet 104:67-83

Zhu J (1998) Mixed model approaches for mapping quantitative trait loci. Heriditas (Beijing) 20(Suppl):137-138 